(C) 1991 ISIJ

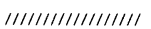

論 文

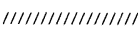

中炭素低合金鋼の変態挙動に及ほす引張応力 付加の効果

\author{
金築 裕 $^{*} \cdot$ 戒田 收 ${ }^{* 2} \cdot$ 鹿礒正人 $* 3 \cdot$ 勝亦正昭 $*$
}

\title{
Effect of Applied Tensile Stress on the Transformation Behavior of Medium Carbon Low Alloy Steels
}

Yutaka Kanetsuki, Osamu KaIDA, Masato KaISO and Masaaki Katsumata

\begin{abstract}
Synopsis :
In order to accelerate the ferrite-pearlite transformation of medium carbon low alloy steel bars, the possibility of controlling the transformation behavior by application of the tensile stress during cooling after rolling was investigated. Tensile stress was applied by controlling the strain rate considering the stress drop due to relaxation. It was found that acceleration of ferrite transformation was occured by developed method. This results proved this method to be effective for softening the rolled bars. Furthermore, increase of uniform elongation up to about $60 \%$ occured in the case of straining during transformation. Discussion was focussed on the role of the applied stress and it was concluded that applied stress increased the internal stress of the austenite and resulted in the increased nucleation rate of ferrite transformation.

Key words : medium carbon low alloy steel; tensile stress; CCT diagram; ferrite transformation; formability.
\end{abstract}

\section{1. 緒言}

制御圧延，制御冷却技術は高強度高鞁性の鋼板の製造 プロセスとして活用されてきており，最近ではさらに広 範囲な鋼材において, 種々の特性の改善の手段として検 討が進められている. 例えば, 線材, 棒鋼の圧延工程で はこれまで圧延後の制御冷却が主体であったが，制御压： 延を組み合わせることにより，冷間での加工性の改善を 狙った軟質組織の棒鋼の製造が検討されてきている，著 者らは中炭素鋼の球状化処理の簡略化のための前組織の 調整に対して制御压延，制御冷却技術の適用が効果があ ることを報告した1).すなわち，制御压延，制御冷却に よりフェライト・パーライト組織を微細にすることが叮 能であり，微細化したフェライト・パーライト組織の場 命，球状化処理時間を簡略化した場合でも良好な球状化 組織が得られることを示した。

しかしながら，焼入性の高められた低合金中炭素棒䤱 においては压延後の空冷においても硬いベイナイト組織 となり加工性に難点がある。また球状化処理を施した場
合もフェライト・パーライト組織に比べ軟質な球状化組 織が得られにくい。このため庄延後の組織としてフェラ イト・パーライト組織が望まれているが，この組織を得 るためには压延後の冷却速度を著しく逯くするか，また はフェライト・パーライト変態を促進させる必要がある. 後者の場合，その手段として压延㨁後のオーステナイト 粒度を微細にする方法，または来舟結昆域で加1する才 法があるが，微細化したオーステナイト結获粒を変態温 度まで保持するためには急冷する必要があり，また，後 者の末再結晶域圧延では組織は著しく買方性化し，冷䦌 加工性の観点からは望ましくない.

そこで，本研究では制御压延に代えて変態促進効果が 知られている引張忍力を变態前に与え, 公冷の冷却速度 で組織をフェライト・パーライト組織に制御するオ法の 叮能性を検討した。変態は外部からの忍力に影響をうけ ることは良く知られている。例えば，用力の場令は才ー ステナイトの安定化効果が知られている。これまでの研 究により, 压力下での平衡状態汹, TTT 汹, CCT 汹が

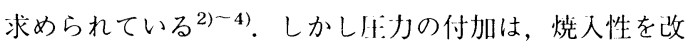

平成 2 年 4 月本会講演大会にて発表 平成 2 年 6 月 25 日受付 (Received June 25, 1990)

* (株)神戸製鋼所鉄鋼技術研究所 I. 博 (Iron \& Steel Research Laboratories, Kobe Steel, Ltd., 1-3-18 Wakinohama-cho Chuo-ku Kobe 651)

*2 (株)神戸製鋼所神万製鉄所（Kobe Works, Kobe Steel, Ltd.)

*3 (株)神戸製鋼所鉄鋼技術研究所（Iron \& Steel Research Laboratories, Kobe Steel, Ltd.) 
Table 1. Chemical compositions of the steels used (wt $\%$ ).

\begin{tabular}{c|cccccccc}
\hline Steel & $\mathrm{C}$ & $\mathrm{Si}$ & $\mathrm{Mn}$ & $\mathrm{P}$ & $\mathrm{S}$ & $\mathrm{Cr}$ & $\mathrm{Mo}$ & $\mathrm{Ni}$ \\
\hline SCM418 & 0.20 & 0.18 & 0.77 & 0.008 & 0.012 & 1.19 & 0.16 & 0.02 \\
SCM435 & 0.36 & 0.20 & 0.77 & 0.008 & 0.012 & 1.05 & 0.17 & 0.01 \\
\hline
\end{tabular}

善するためには有効であるが，变態を促進する目的には 不適当である。一方, 引張心力の場合には変態促進効果 があることが知られている(5)ー7). たとえば， РОRTERら は付加する応力には約 $5 \mathrm{kgf} / \mathrm{mm}^{2}$ のしきい值が存在し ており，変態を促進するためにはしきい值以上の忍力付 加によって変態が促進されることを示している6). しか しながら，ほとんどの研究が等温変態についての結果で ありに業的に適用することが比較的欲易な連続冷却変態 に関してはほとんど明らかにはされていない。

そこで本研究では変態直前でしきい值以上の十分な伈 力付加の力法を検執するとともに，変態挙動に及ぼす効 果を明らかにすることを目的とした。

\section{2. 実 験 方 法}

\section{$2 \cdot 1$ 供試銅}

Table 1 に供試鋼の化学城分を示す。供試鋼は機械構 造用鋼として典型的な SCM418, SCM435 鋼である. 遖径 $40 \mathrm{~mm}$ の比延丸棒を消径 $20 \mathrm{~mm}$ に熱間鍛造し, そ の後焼準を行った。

\section{$2 \cdot 2$ 応力制御引張試験}

引張忍力の付加装置としてインストロンタイプの引張 試験機を用いた。試験片は㨁径 $6 \mathrm{~mm}$, ゲージ長 $30 \mathrm{~mm}$ とし，焼準後機械加Iにより製作した。試料の加熱およ び冷却速度の制御には, 試験機に取り付けた赤外線加熱 炉を用いた. SCM418 および SCM435 の試料をそれぞ れ $880^{\circ} \mathrm{C}, 860^{\circ} \mathrm{C}$ で $1 \min$ のオーステナイト化処理を 行った後, 連続冷却し, 冷却中に引張試験機により引張 忍力を与えた。冷却速度は $240^{\circ} \mathrm{C} / \mathrm{min}$ から $30^{\circ} \mathrm{C} / \mathrm{min}$ の範讲で変化させた．Fig. 1 は本実験で用いた供試鋼の CCT 曲線を示している.オーステナイト化条件は引張 試験の場合と闹じ条作とした。眓中に示した泠却速度が 忍力制御引脹陚験での冷却速度である。この冷却速度の 範用でフェライト，パーライト変態に及ほす心伈付加の 効果を検討した，フェライト变態直前の温度, $800^{\circ} \mathrm{C} て ゙$ 効果的な伈力を付加するための予備的検封として $800^{\circ} \mathrm{C}$ 前後の一定温度でのオーステナイトの機械的性質をあら かじめ通常の引張試験（歪み速度 $\fallingdotseq 1 \times 10^{-4} / \mathrm{s}$ ) で求 めた。通常行われる一资の歪み速度での引張試験に対し， $3 \cdot 1$ 節で述べる桠み速度を調整し温度に対して一定の応

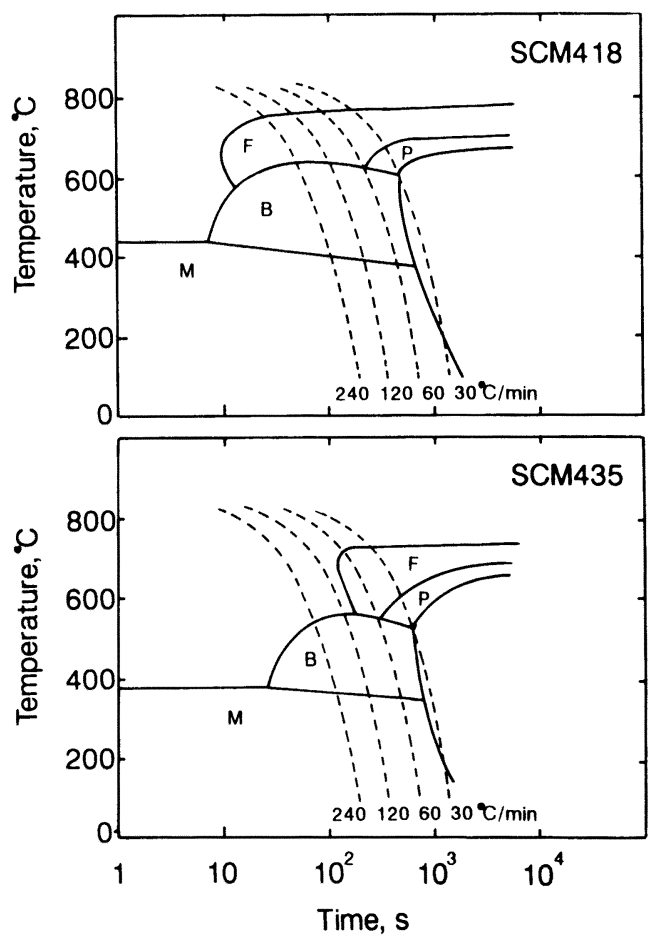

Fig. 1. CCT diagrams of the steels used. Cooling rate of stress controlled testing performed are shown in these diagrams.

力付加速度で变形を行った本方法を応力制御引張試験と 呼び, 通常の試験を歪み制御引張試験と呼び区別した。

\section{3. 実 験 結 果}

\section{$3 \cdot 1$ 熱間でのオーステナイトの機械的性質}

試料に引張応力を与える方法として重錘を用いる方法 が一般的であるが，連続冷却中では試料の強度が連続的 に変化し特に高温側で低強度であるため一定荷重では高 い忘力を付与することは困難である。そこで連続冷却中 の変態直前に引張応力を有効に付加する方法を次のよう に検討した。まず安定，および過冷オーステナイト状態 での降伏㐫力, 引張強さを測定した。また熱間では心力 緩和が著しいことから，Fig. 2 の上部に示した方法，す なわちオーステナイト化の温度で $5 \%$ の塑性変形後クロ スヘッドを止める方法により応力緩和挙動を求めた。す なわち, Fig. 2 は $5 \%$ の変形を与えたのち $60^{\circ} \mathrm{C} / \mathrm{min} て ゙$ 冷却中の心力緩和挙動を示しているが，応力緩和は $\mathrm{SCM} 418$ 鋼では $815^{\circ} \mathrm{C}, \mathrm{SCM} 435$ 鋼では $800^{\circ} \mathrm{C}$ までは 急激に起こり，その後は応力緩和は起こらず冷却による 収縮が上回ることがわかった。この温度を以下では SS 


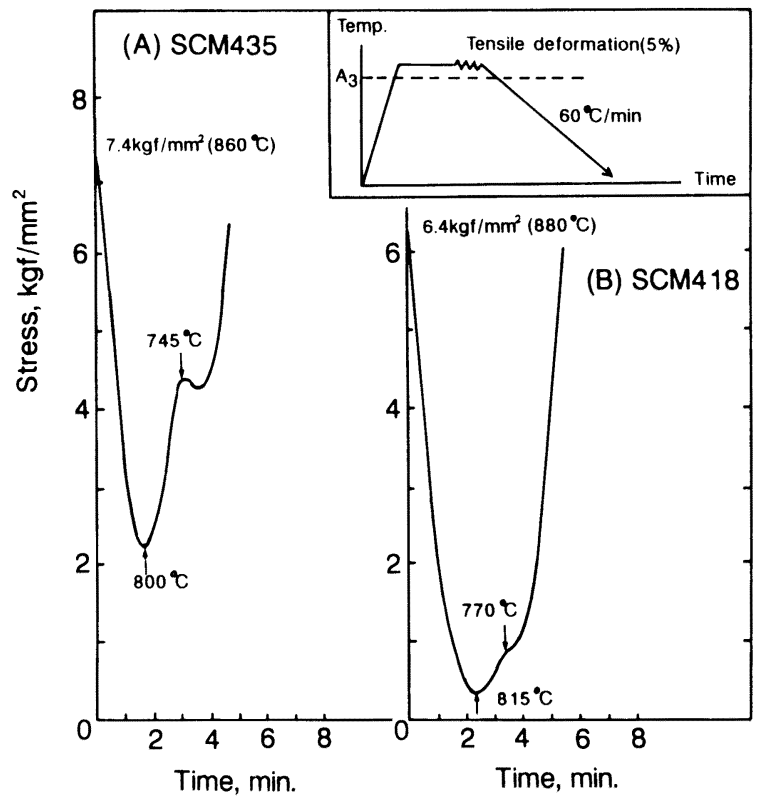

Fig. 2. Stress relaxation behavior of the steels used during continuous cooling.

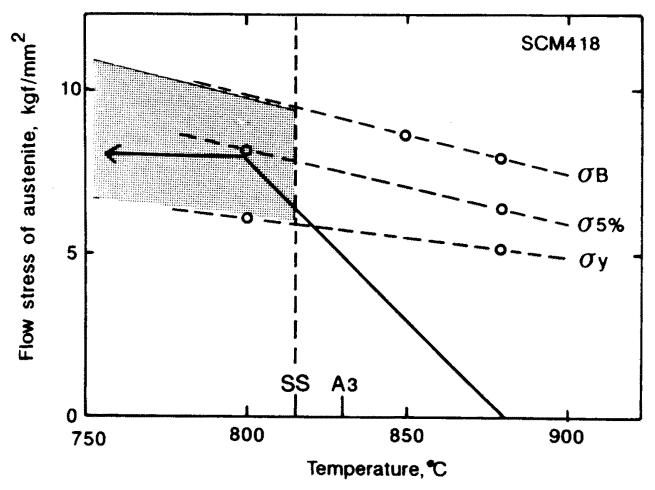

Fig. 3. Temperature dependence of yield and flow stress of austenite. Solid line indicates the path of loading during continuous cooling and hatched area shows the region without stress relaxation. $\mathrm{SS}$ temperature is shown in Fig. 2.

（Softening Stop）点と呼ぶが, SS 点以下の冷却中, $\mathrm{SCM} 418$ 鋼で $770^{\circ} \mathrm{C}, \mathrm{SCM} 435$ 鋼で $745^{\circ} \mathrm{C}$ に変曲点が 認められた。これらの 2 番目の変曲点は, Fig. 1 のフェ ライト変態開始温度に対応していることから,フェライ 卜変態時の体積変化によるものであると考えられる.

そこで,Fig. 3 に SCM418 鋼のオーステナイト状態 での機械的性質と SS 温度の関係を示している. Fig. 2 の結果より $\mathrm{SS}$ 点 $\left(815^{\circ} \mathrm{C}\right)$ 以下の温度では応力緩和が 起こらないため, 引張強さ近傍の応力 (約 $10 \mathrm{kgf} / \mathrm{mm}^{2}$ )
まで大きな塑性変形を伴わず付加できることがわかっ た．図中のハッチ部が本実験で検討した領域を示してい る.また図中の実線は冷却中の忘力付加経路を示してい る.すなわち変態点まで塑性変形を与えないよう降伏応 力以下で，また異なる冷却速度の場命も同一の経路にな るよう温度に対して值線的に応力を付加した，その方法 として，SS 点以上の忍力緩和が大きい領域では緩和速 度をやや上回る歪み速度で引張り，また温度の低下とと もに変化する緩和速度に対応して歪み速度を段階的に変 化させることにより対応した。

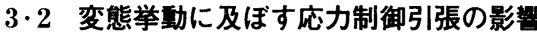

Fig. 4 は応力制御引張試験の結果を伈力と温度の関係 で示している. 図中の破線は Fig. 3 のハッチで示した しきい值 $\left(5 \mathrm{kgf} / \mathrm{mm}^{2}\right)$ 以上で変形が均一に起こる本実 験の目標応力レベルを示している。また网中の引張速度 は目標応力値に対応する引張速度であり, SS 温度以下 の温度域では变化させず一定速度の引張変形である.

Fig. 4(A)，（B）はそれぞれ SCM418，SCM435 鋼の いずれも $120^{\circ} \mathrm{C} / \mathrm{min}$ で連続冷却した場合の結果を示し ている。この冷却速度では Fig. 1 の CCT 図より明ら かなように SCM418 鋼では冷却中にフェライト変態点 を通過する. Fig. 4 (A) において応力は変態点に対応す る温度で変曲点を示し，その後再び増加する挙動がい ずれの変形速度においても認められた。この挙動は LIEBAUT らが示している挙動と同じであり ${ }^{8)}$, 明らかに フェライト変態によって起こったものである。一方, 


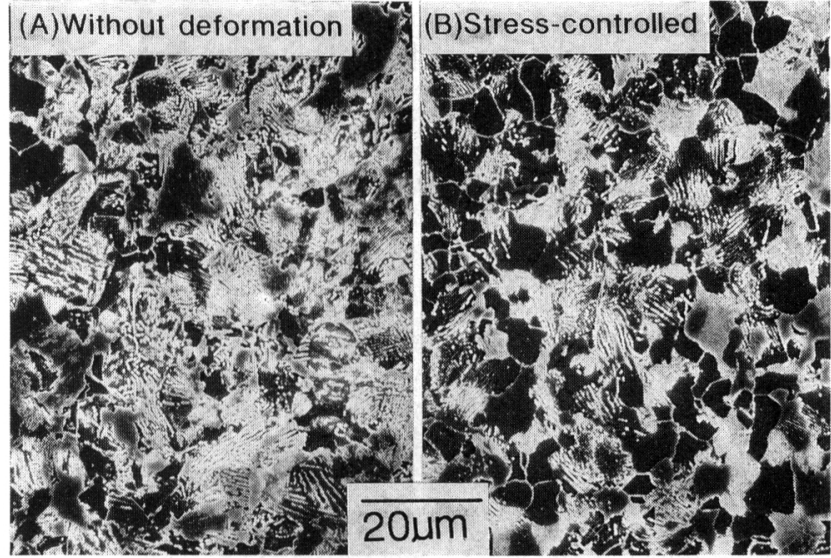

$\operatorname{SCM} 435\left(240^{\circ} \mathrm{C} / \mathrm{min}\right.$

Photo. 1. SEM micrographs showing the effect of stress controlled tensile testing. Photo (A) shows the mixed microstructure of bainite and martensite obtained by cooling at $240^{\circ} \mathrm{C} / \mathrm{min}$ without deformation. Photo (B) shows the change in microstructure due to application of stress controlled straining at $1 \times 10^{-4} / \mathrm{s}$. Note that the ferrite grains are observed in Photo (B).

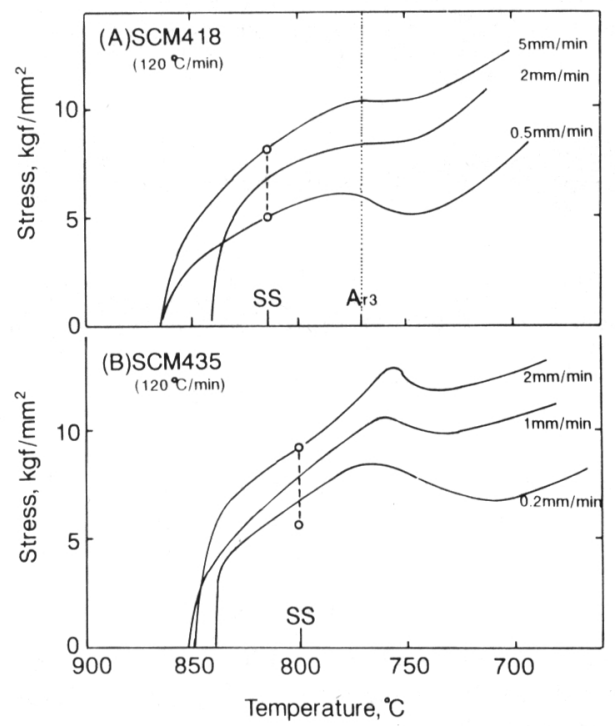

Fig. 4. Stress-temperature curves obtained by the stress controlled tensile testing. Broken lines at SS temperature show the stress range which were achieved by stress controlled straining.

SCM435 鋼においても同様の挙動が観察された。また, ここには示していないが $240^{\circ} \mathrm{C} / \mathrm{min}$ でも同じ挙動が認 められた。このことは SCM418 鋼とおなじようにフェ ライト変態が起こっていることを示唆している. Photo. 1 は SCM435 鋼の冷却後の組織を SEM (走査型電子顕 微鏡）によって観察した結果を応力を付加しない場合と 比較して示している．応力を付加しない場合 (A), ベ イナイトを主体とし一部マルテンサイトを含む組織であ るのに対し，応力制御を行った場合 (B)はフェライト (黒く見える部分) 変態していることが認められた.
Photo. 2 にそれぞれの TEM (透過電子顕微鏡) 観察結 果を示している。また両者の差異は次に示すように硬 度からも確認された。これらの結果はFig. 4(B)の SCM435 鋼の応力低下も SCM418 鋼と同じくフェライ ト変態が誘起されたことによることを示している.

次にFig. 4 に示した変形条件で引張変形を行い, そ の泠却途中の忍力低下を示してからの各温度で除荷し, そのときの塑性变形量と室温での硬さの関係を示したの がFig. 5 である. SCM418 鋼では硬さはほぼ一定で変 形量で示している除荷のタイミングの影響は認められな かった。これは SCM418 鋼では応力無付加でもフェラ イト変態が起こるため組織変化を伴わず硬度には変化が みとめられないと考えられる。しかしながら， SCM435 鋼では著しい軟化が約 $1 \%$ で起こりそれ以上の変形量で は軟化の変形量依存性は小さいことがわかった。軟化は フェライト変態が誘起されたことによることはPhoto. 1 からも明らかである。 したがって, 変態開始後の除荷 はフェライト変態の進行に影響を与えず，変態直前の応 力の有無が変態促進に大きく関与していると考えられ る.

Fig. 6 は本実験結果を CCT 四で表現したもので, 引 張忍力付加により矢印で示すようにフェライト変態が促 進されると考えることができる. フェライト変態の後に パーライト変態が一部起こっていることは Photo. 1 で 認められたが泠却曲線および Fig. 4 の応力・温度曲線か らはパーライト変態の開始点の温度を分離できなかっ た。この点についてはさらに精密な測定が必要である。

\section{$3 \cdot 3$ フェライト変態と歪み速度の関係}

$3 \cdot 2$ 節の SCM435 鋼の結果は, 変態誘起に対しては $1 \%$ 以上の変形量は基本的には大きな役割を果たしてい 


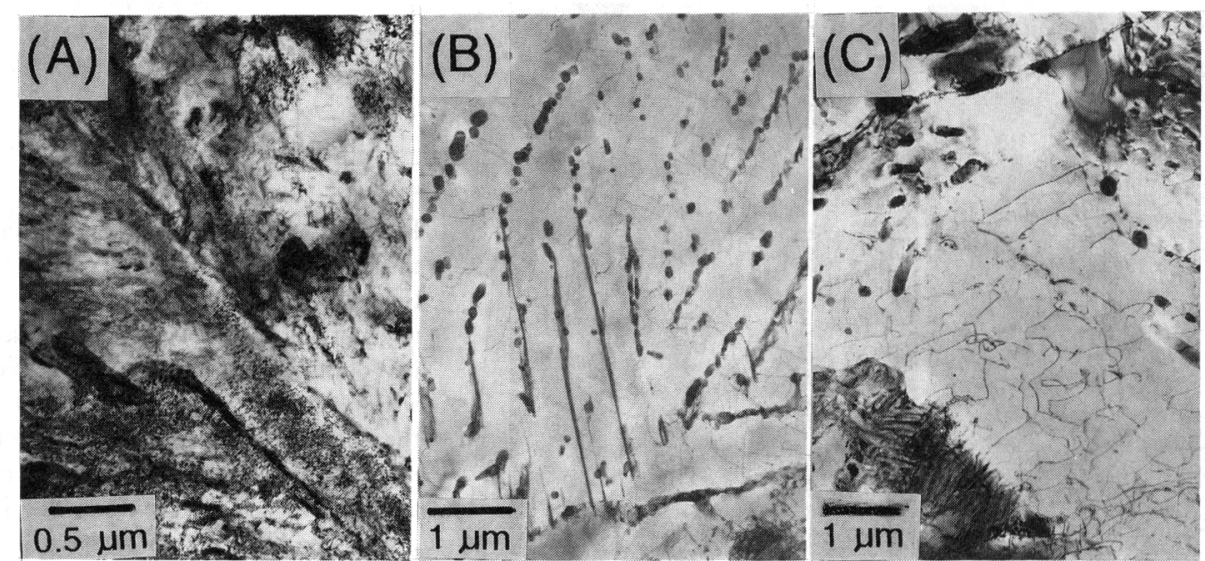

Photo. 2. TEM micrographs of martensite (A), bainite (B) and ferrite (C). Martensite and bainite were observed for specimen shown in Photo. 1(A), and ferrite was observed for specimen shown in Photo. 1(B).

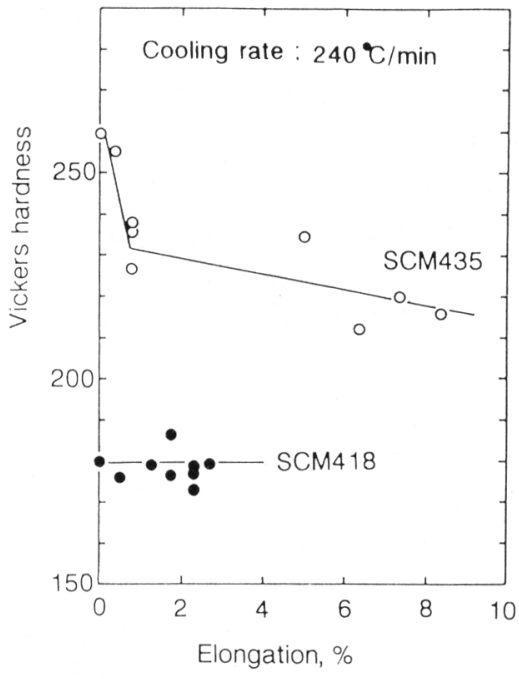

Fig. 5. Relation between the hardness and the elongation obtained by unloading at each period during stress controlled tensile testing. Cooling rate and strain rates after SS temperature were $240^{\circ} \mathrm{C} / \mathrm{min}$ and $1 \times 10^{-4} \sim 1 \times 10^{-3} / \mathrm{s}$ respectively.

ないことを示唆している。また，フェライト変態はフェ ライト変態開始前の応力レベルが $5 \mathrm{kgf} / \mathrm{mm}^{2}$ 以上では 応力レベルには関係なく起こる。しかしながら, 変態開 始応力は歪み速度に大きく依存している. そこで歪み速 度がさらに速くなった場合の検討を次に示す方法で行っ た。すなわち Fig. 4 に示した歪み速度以上では変態前

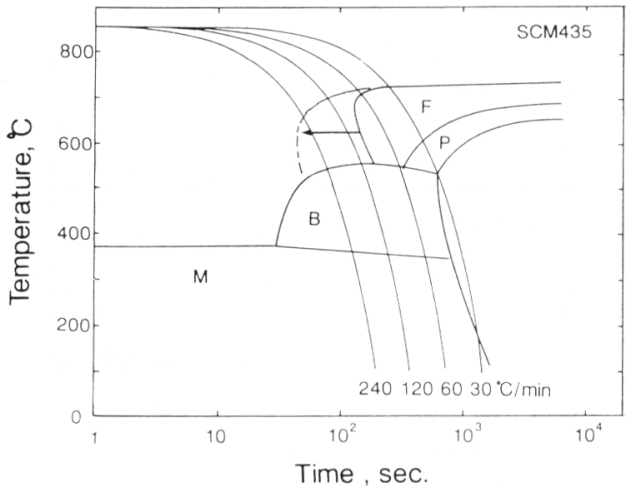

Fig. 6. Illustration of the effect of stress controlled tensile testing using CCT diagram. Arrow indicate the shift of the ferrite nose.

に試料が破断するため, 歪み速度を変態直後に急変させ る二段階に分けた。

Fig. 7 は SCM418 鋼について,まず $880^{\circ} \mathrm{C}$ から $780^{\circ} \mathrm{C}$ までを $30^{\circ} \mathrm{C} / \mathrm{min}$ で冷却し，この間は応力制御を 行い変態直前の忍力を $10 \mathrm{kgf} / \mathrm{mm}^{2}$ に調整した。このと きの歪み速度は $2.6 \times 10^{-3} / \mathrm{s}$ である。その後は温度を $780^{\circ} \mathrm{C}$ 一定としその温度で引きつづいて引張変形した。 その時の歪み速度を变えた場合の忍力-歪み曲線を示し ている。

曲線（a）は $780^{\circ} \mathrm{C}$ 以降も歪み速度を変えず変形を 行った場合の結果を示している，応力は歪み量と共に単 調に低下を示し，約 $60 \%$ の変形量で忍力は急激に低下 し破断した. Photo. 3 は試験前打よび急激な訬力低下 


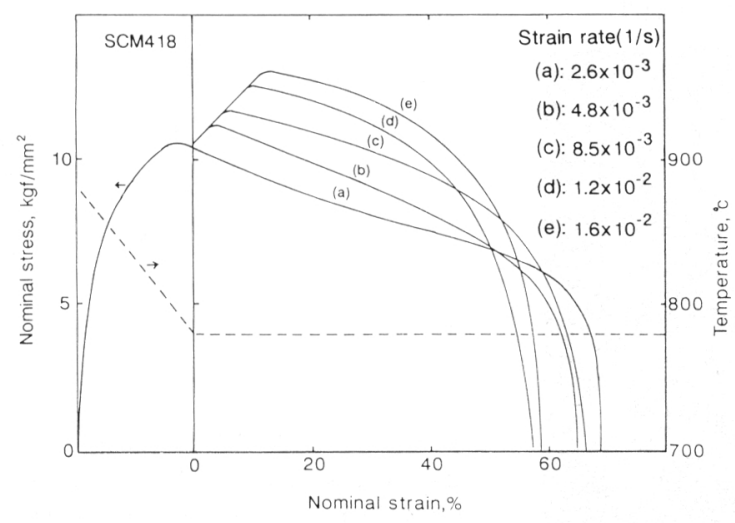

Fig. 7. Effect of the strain rate on the stress-strain curves at $780^{\circ} \mathrm{C}$. Left part shows the initial stress controlled testing during continuous cooling at a cooling rate of $30^{\circ} \mathrm{C} / \mathrm{min}$ from $880^{\circ} \mathrm{C}$ to $780^{\circ} \mathrm{C}$.

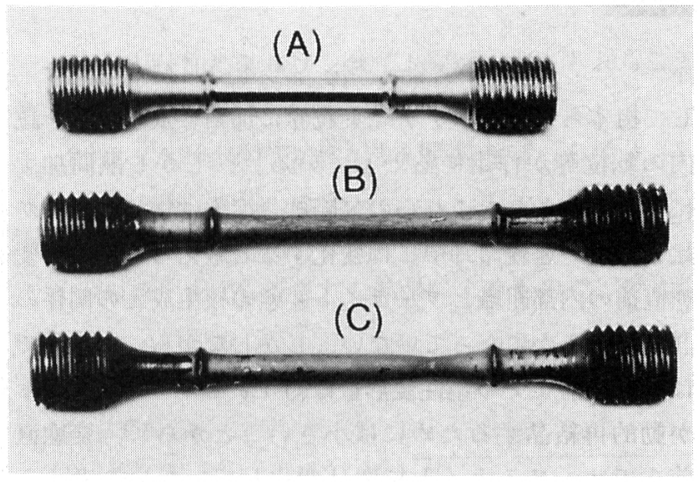

(A) Before testing (B) (C) During the testing

Photo. 3. Change in testpiece. Testing condition is indicated in Fig. 7 (a).

を示す歪みの前後での試験片の形状変化を示したもの で, 約 60\%の均一伸びを示し, 破断前の急激な荷重低 下がネッキングによるものであることがわかった。曲線 (b)〜 (e) は歪み速度を急変したことにより, 再び応力 ピークを示した後, 単調に応力が低下する曲線 (a) と 同様の挙動を示すとともに（a）の場合と同様に50 $60 \%$ の均一伸びを示した. 比較のため $820^{\circ} \mathrm{C}$ (二相域) および $850^{\circ} \mathrm{C}$ (オーステナイト域)で加熱保持し引張变 形を行った場合の均一伸びはそれぞれ $12 \%$ および $20 \%$ であり著しく異なった結果である。フェライト変態の開 始はいずれも最初の応力のピークに対応しているが，終 了点は検知できなかった。しかし歪み速度が速くなるに つれて破断までの時間は短時間になるが，ほほ同程度の 伸びを示していることから，恋態が変形と同期している ことを示唆している.

Fig. 8 はピーク応力と歪み速度の関係を示している が, 直線関係が認められると共に, その傾きから得られ た $m$ 值は 0.18 である. 低炭素鋼で求められている值

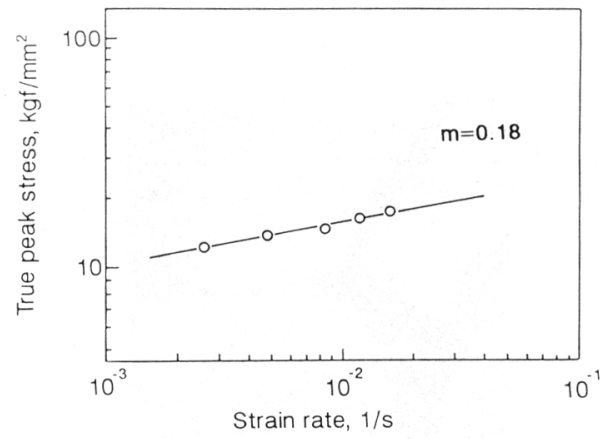

Fig. 8. Relation between the true peak stress and the strain rate shown in Fig. 7.

は $900^{\circ} \mathrm{C}$ で $0.11,1200^{\circ} \mathrm{C}$ で 0.18 であり ${ }^{9)}$, 後者と同 じ高い值である。

Photo. 4 (B) は応力を付加しない場合（A) と比較し て示した SCM418 鋼の組織変化を示している. 応力付 加により, フェライト粒が等軸で, かつ著しく微細化し 粒界は湾曲していることが認められた．Photo. 5 はさ らに TEM で観察した結果で微細フェライト粒を示して いる．粒内の転位密度は小さい。試料は破断後は空冷し ており変形直後の組織を凍結していない可能性がある が, 結晶粒は微細である,これらの結果はフェライト変 態の核生成, 粒成長が塑性変形に大きな役割を果たすと ともに微細化した組織の効果も併せて大きな均一伸びを 示したものと考えられる.

\section{4. 考察}

本研究結果として, 連続冷却中に応力制御引張を施す ことにより変態前に $5 \mathrm{kgf} / \mathrm{mm}^{2}$ 以上の応力を付与する ことが可能で, またその効果としてフェライト変態が著 しく促進されることがわかった．以下この点について考 


\section{(A)Without deformation (B)Stress-controlled}

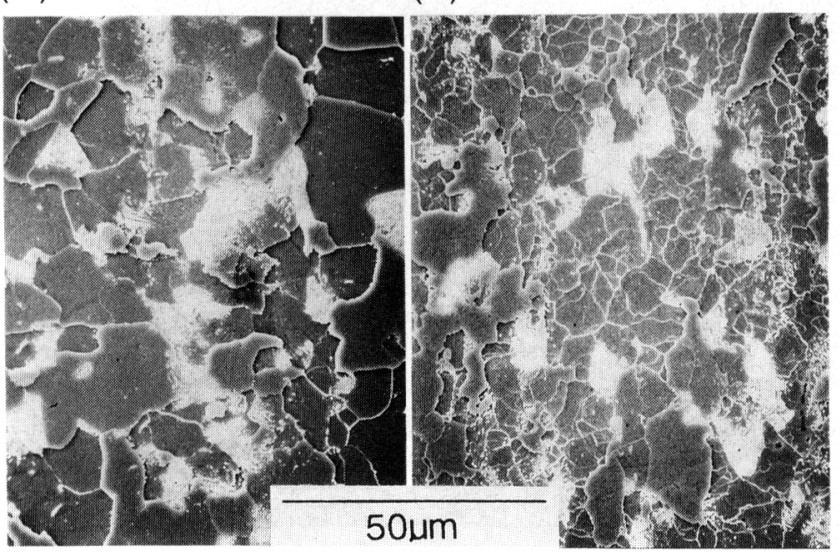

Photo. 4. SEM micrographs showing the microstructural change by stress controlled tensile testing shown in Fig. 7.

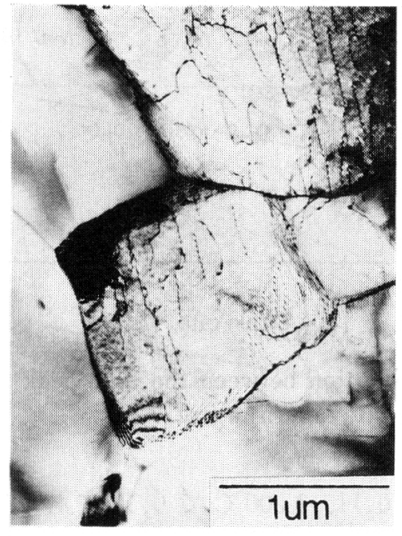

Photo. 5. TEM micrograph showing the fine ferrite grains obtained by stress controlled tensile testing of steel SCM418 shown in Fig. 7 (a).

察する.

フェライト変態促進効果については，これまで制御厂 延によるもの，応力付加によるものが報告されている. 中炭素鋼に打ける制御圧延の効果については KASPERら によって検討がなされ CCT 濦の変化を求めている ${ }^{10)}$. その結果フェライト変態が熱間加工温度の低下ととも に，すなわちオーステナイトを末再結晶域で加上した場 合に著しく促進されることを示している.また動的再結 晶後 $10^{\circ} \mathrm{C} / \mathrm{s}$ 以上で泠却することによりフェライト変態 が促進される効果が顕著になることを著者らは既に報告 している ${ }^{1)}$ 。これらの原因として，オーステナイト粒の 微細化による核生成サイトの増加, および残留歪みの二 つの効果によるものと考えられている。核生成サイトと
して梅本らはオーステナイト粒界に加えて双晶境界, 粒 内の転位等が作用するとしている11)。しかし熱間加I： により導人されたこれらの欠陥は急冷では保持できるが 比較的遅い連続冷却中には変化すると考えられ，また変 態直前の内部組織とフェライト变態の核生成との関係の 詳細は明らかになっていない。しかしながら, 本実験で は変態直前までの塑性変形量は約 $1 \%$ とオーステナイト が動的再結晶するためには小さいことから ${ }^{12)}$, 変態遖 前までオーステナイト粒度は変化していないと考えら れ，本結果であるフェライト変態促進効果に打ける粒 界, 双晶境界等の核生成サイトの増加の影響は小さいも のと考えられる。

一方変態までの塑性変形の効果について既に報告がな されているが $10 \%$ 程度までは歪み量とともに恋態まで の潜伏期間が直線的に減少することが羿められてい る7)。しかしながら本実験ではフェライト変態の変形量 との関係はこれまでの報告の結果とは異なっており，

Fig. 5 の結果は $1 \%$ のわずかな変形量 (SS 温度から変 態までは $0.2 \%$ 程度)でも既に効果が認められている。 したがって, 本実験の結果は, 変態促進効果が変形量で はなく忍力によってもたらされたものであることを示唆 している.

忘力の効果の具体的なメカニズムについて PORTER ら は次のように考察している6). すなわち, 忘力の付加に より粒界に集積した転位によって粒界に忍力集中が起こ り核生成が促進されるとしている。したがって, 変形後 除荷老行う場合と異なり $5 \mathrm{kgf} / \mathrm{mm}^{2}$ 以上の忍力下では わずかな歪みで変態の核生成に十分な忍力集中が得られ るためと考えられ，本実駼結果についても PORTER らが 示唆した機構によるものと推察される. 
またフェライト変態が起こる温度で问時に変形した場 介、組織が著しく微練化し人きな均一伸びをホした。 のことはフェライト変態の核性成が伈力下で継続して進

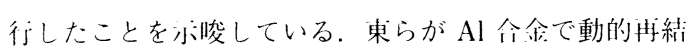

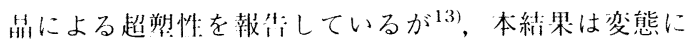
よって超塑性に近い変形が起こっているものと推祭され る。またこのように均・伸びが人きくネッキングを起こ しにくい熙は棒鋼にこの操作を施した場令局近的な変形 を起こしにくいことを意味している.

\section{5. 結言}

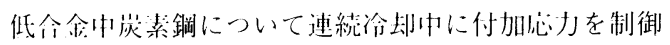

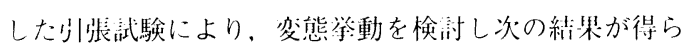
れた。

(1)伈力付加によりフェライト変態が促進されること がわかった。

(2)フェライト変態が変形と间時に起こった場令, 約 $60 \%$ の哇一伸びが得られた。

(1)の䋖果は内部忍力が总力付加により高められフェ ライトの核生成が促進された結果によるもので, 娔入性
の高い低会金中炭素棒鋼の軟質化に対して存効であると 考えられる。

\section{文献}

1) 金築 裕, 勝亦正昭, 澤田裕治: 鉄と鋼, 75 (1989), p. 1178

2 ) T. G. Nil.AN: Trans. AIME, 239 (1967), p. 898

3 ) 藤田旮茯、鈴木正䰻: 鉄と鋼, 57 (1971), p. 1676

4 ) Y. Kanetsuki, $Y$. Hirai and $R$. OgaWa: ISIJ Int., 29 (1989), p. 687

5 ) G. L. Kehl and S. Bhattacharyya: Trans. Am. Soc. Met., $48(1956)$, p. 234

6 ) L. F. Porter and P. C. Rosenthal: Acta Metall., 7 (1959), p. 504

7 ) S. Denis, E. Gautile, S. S.jostrom and A. Simon: Acta Metall., 35 (1987), p. 1621

$8) C h$. Lifbaut, E. Gautier and A. Simon: Mem. Sci. Rev. Met., 85 (1988), p. 571

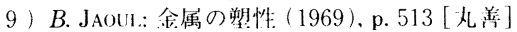

10) R. Kaspar, W. Kapelllner and O. Pawei.Ski: Z. Metallkd., 78 (1987), p. 569

11) M. Umfmoto, $H$. Ohtsuka and $I$. Tamura: Proceedings of International Conference on Physical Metallurgy of Thermomechanical Processing of Steels and Other Metals, Tokyo Japan (1988), p. 769 [ Iron Steel Inst. Jpn.]

12) 徐洲, 酒非 抔: H本金属学会誌, 53 (1989), p. 1161

13) 束 健 ii]: 軽金属, 39 (1989), p. 751 